\title{
Correction to: Adipocytokines and disease progression in endometrial cancer: a systematic review
}

\author{
Irene Ray ${ }^{1,2}$ ([) $\cdot$ Lisiane B. Meira ${ }^{1}$. Agnieszka Michael ${ }^{1,2} \cdot$ Patricia E. Ellis ${ }^{1,2}$
}

(c) Springer Science+Business Media, LLC, part of Springer Nature 2022

\section{Correction to: Cancer and Metastasis Reviews https://doi.org/10.1007/s10555-021-10002-6}

The original published version of this article contained a mistake and the author would like to correct it.

The reference citations inside Table 1 are out of order as the reference citations in the article have been moved around.

The correct presentation of Table 1 is presented on the next page.

The original article has been corrected.

The original article can be found online at https://doi.org/10.1007/ s10555-021-10002-6.

Irene Ray

i.ray@surrey.ac.uk; dr.ireneray@gmail.com

1 University of Surrey, Daphne Jackson Road, Guildford GU2 7WG, UK

2 Royal Surrey NHS Foundation Trust, Egerton Road, Guildford GU2 7XX, UK 


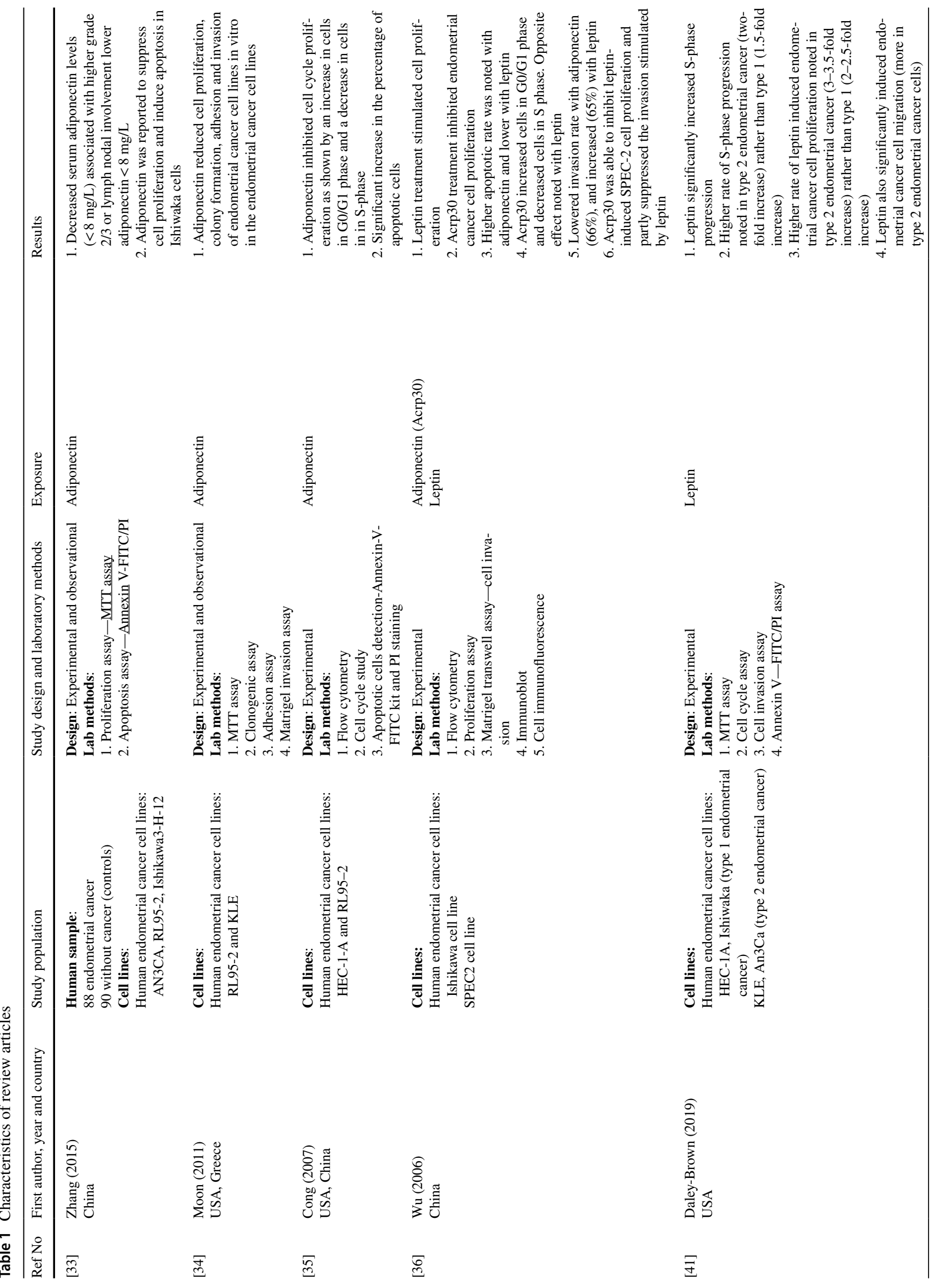




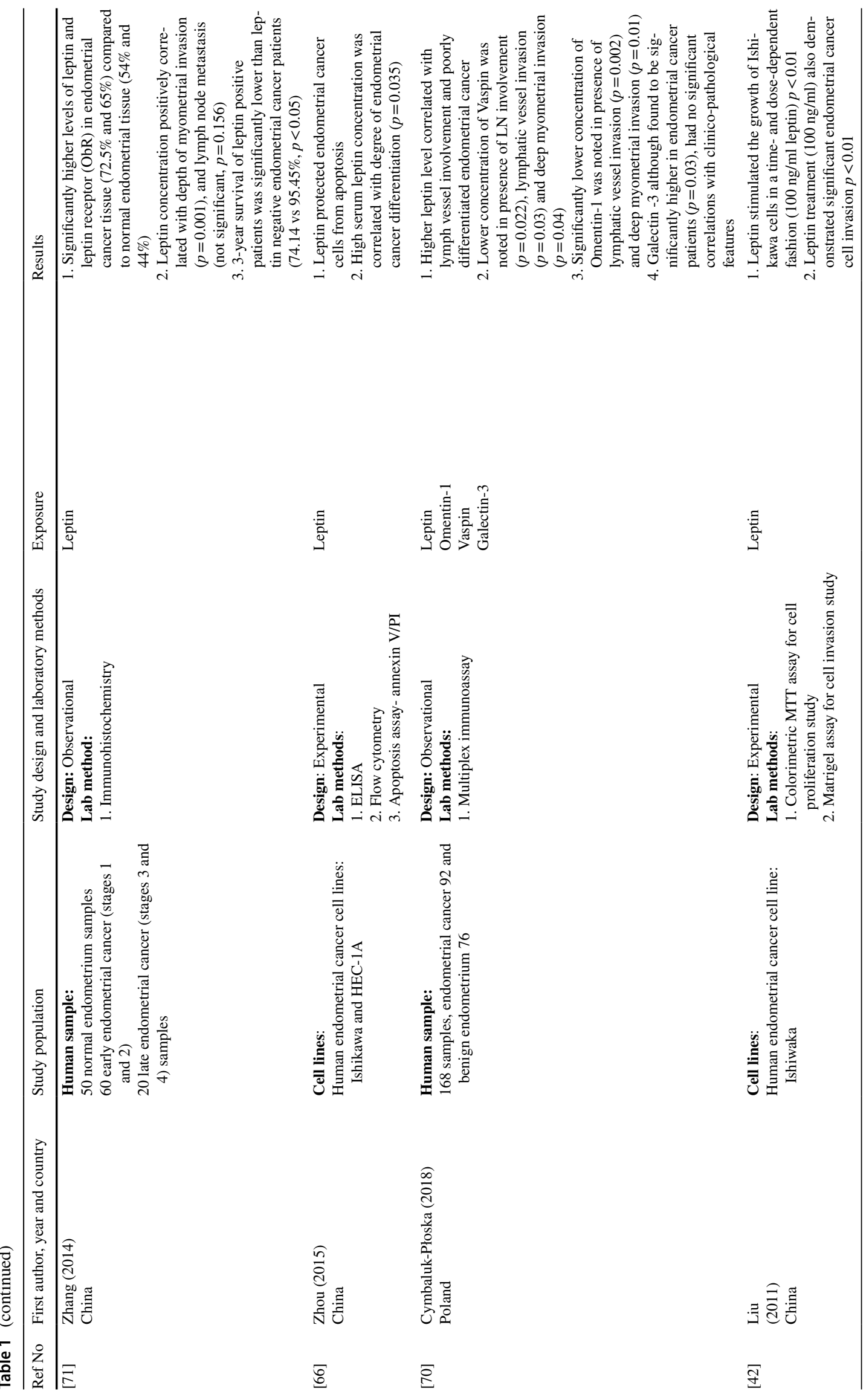




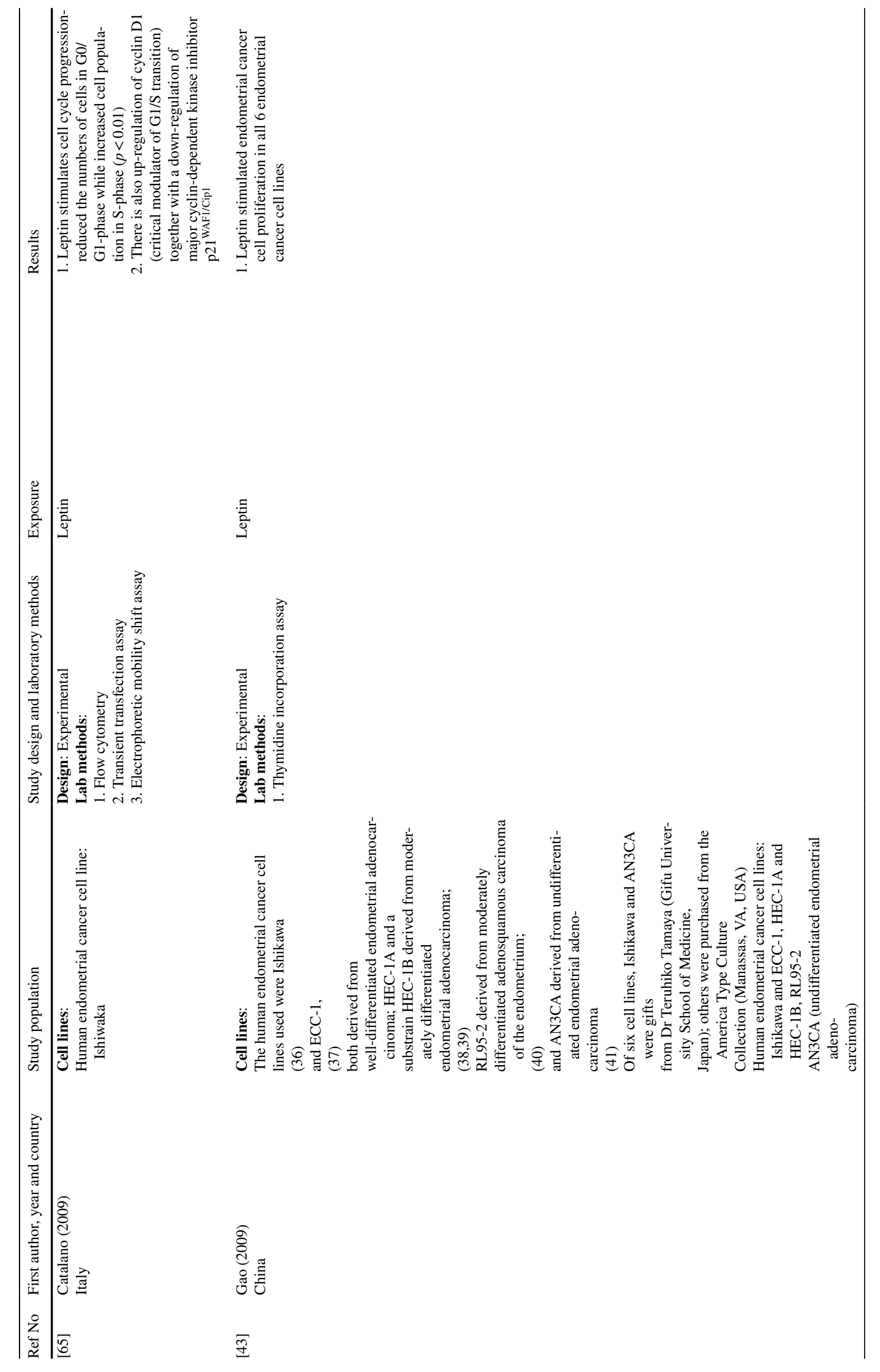




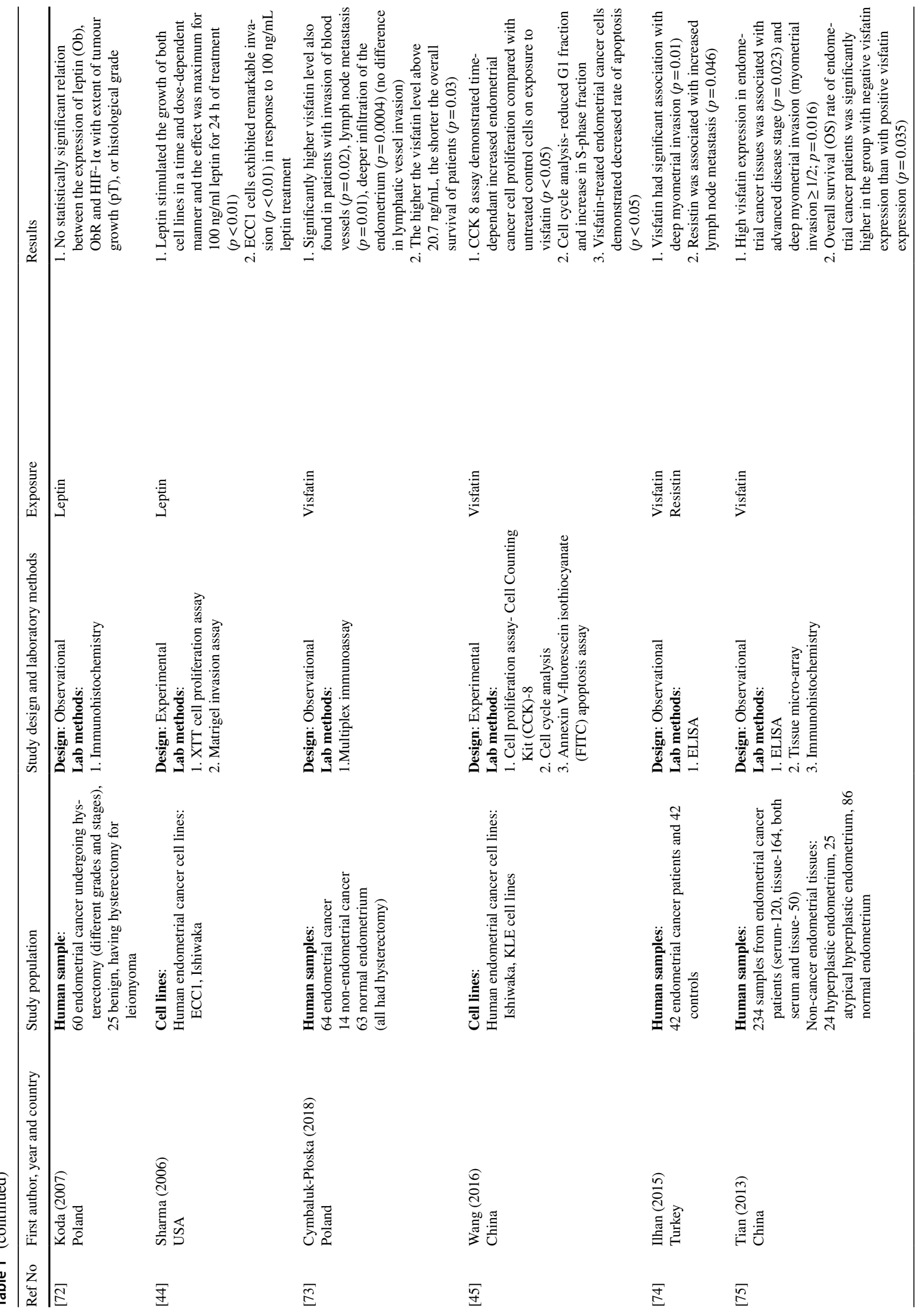




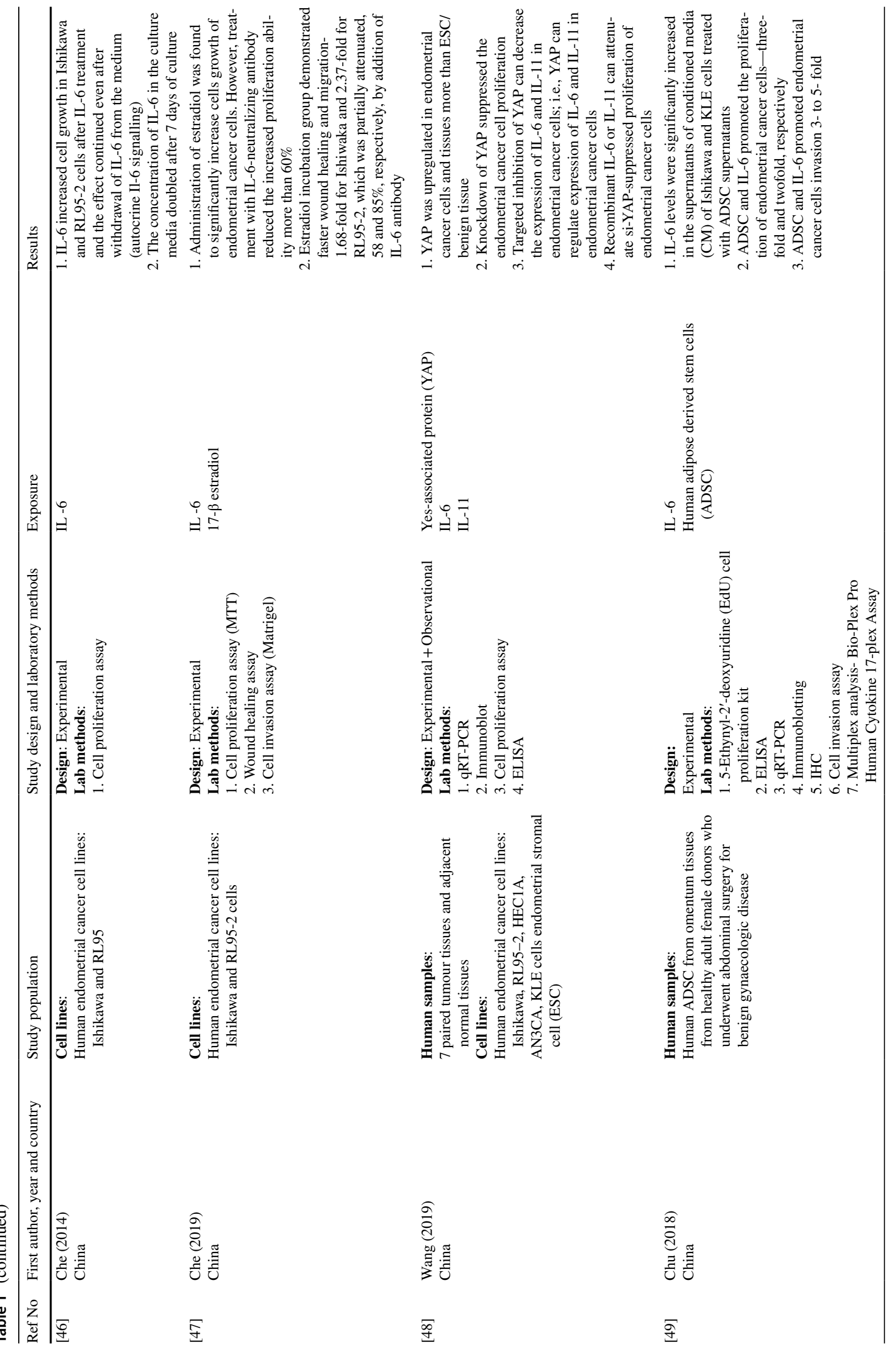




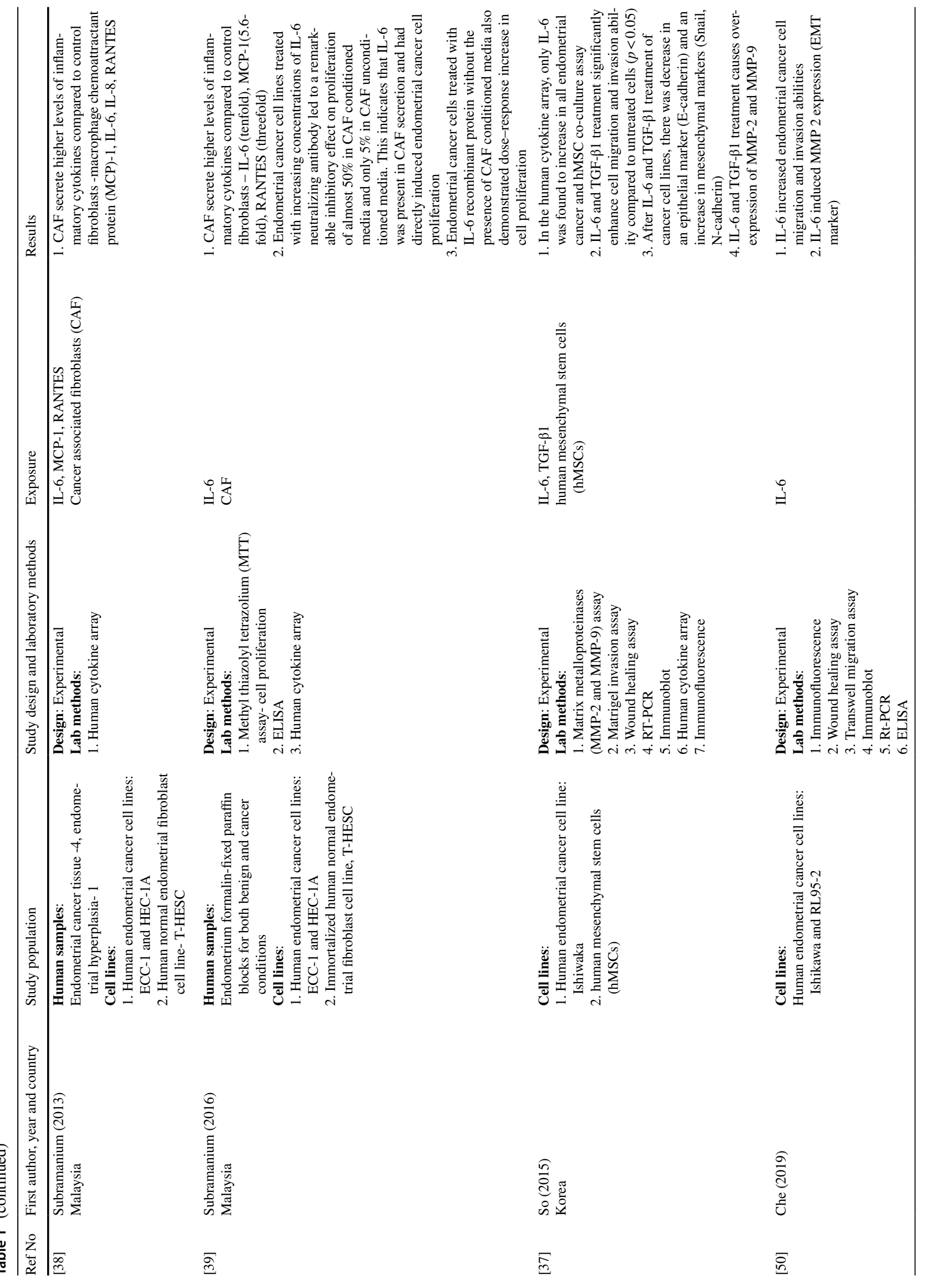




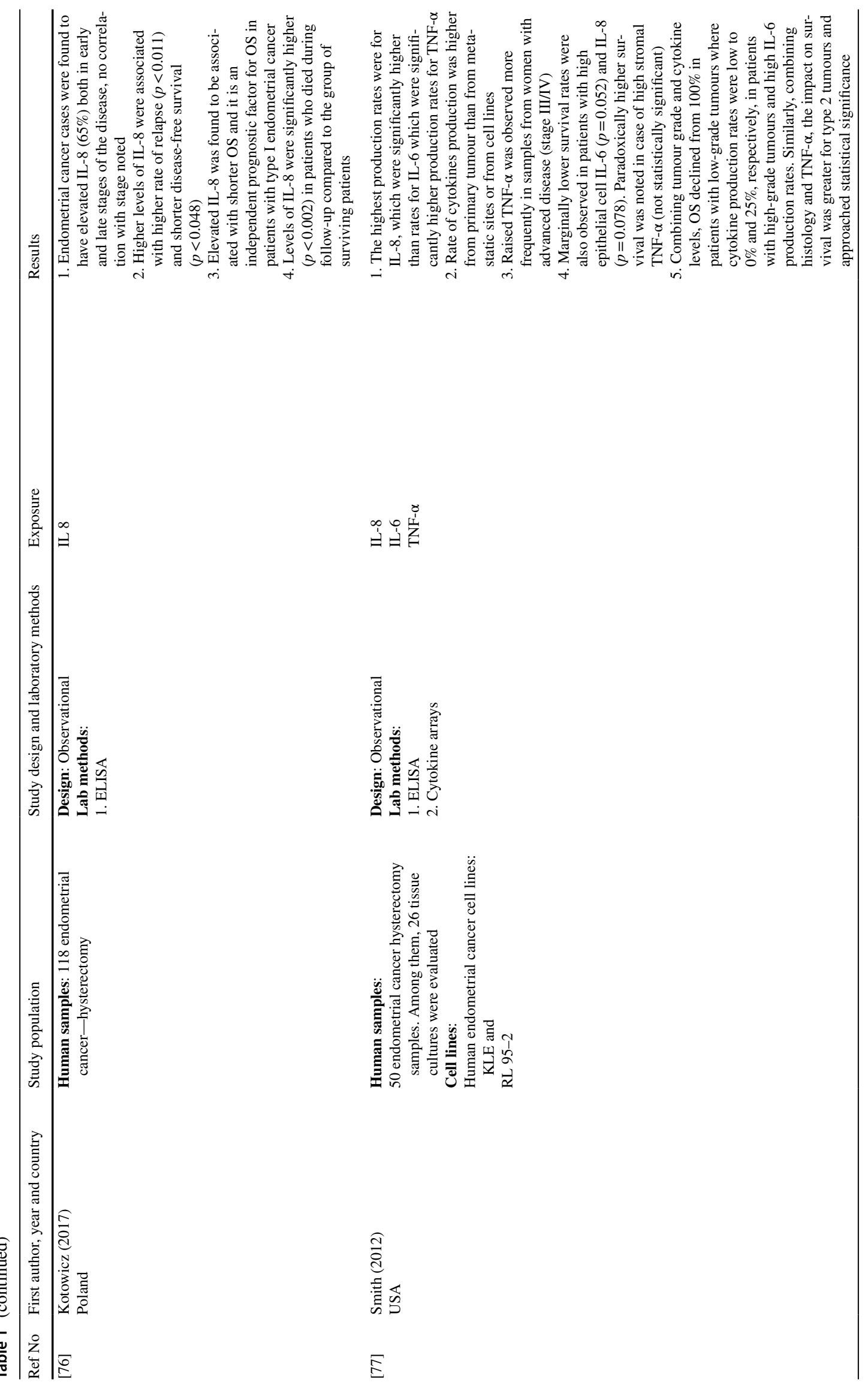




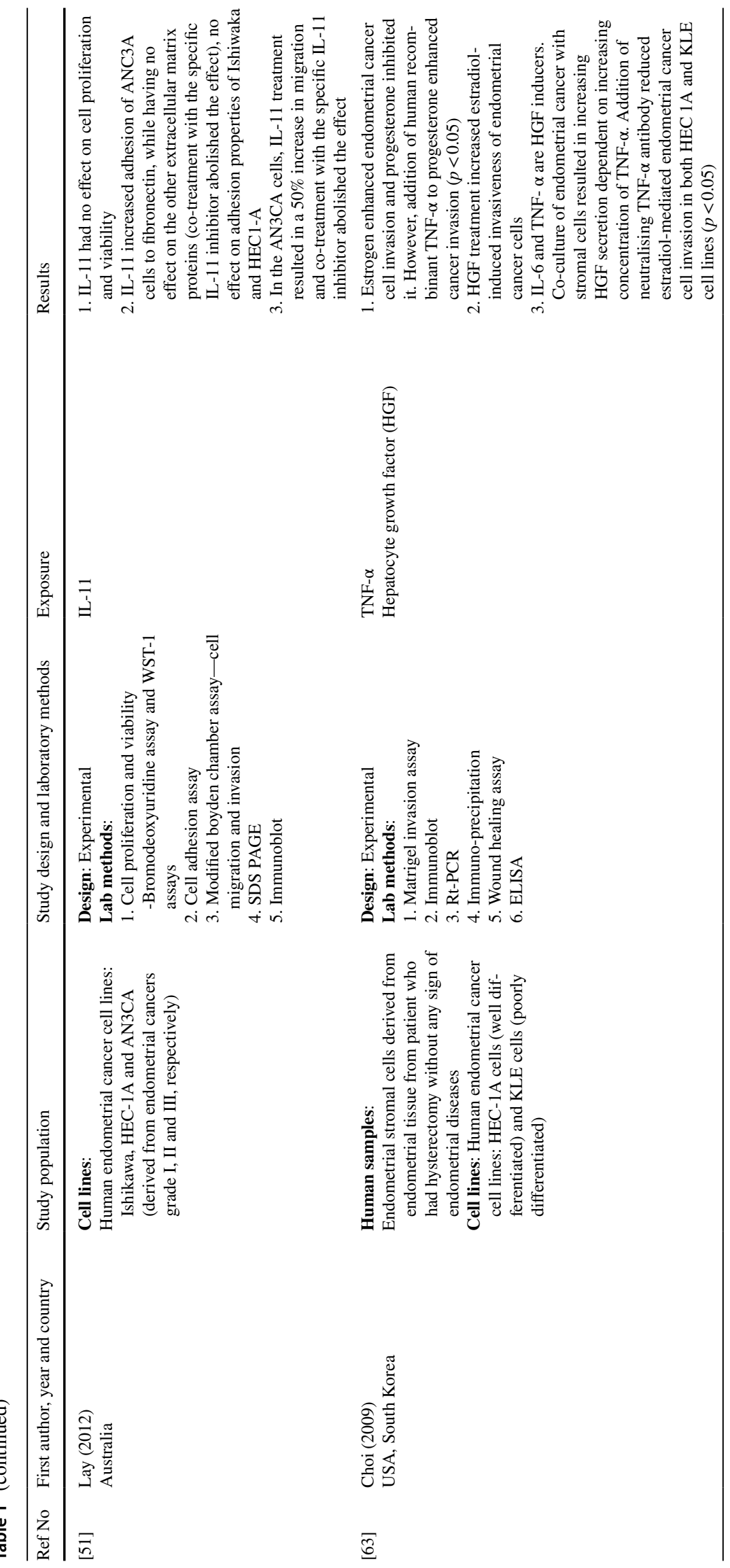




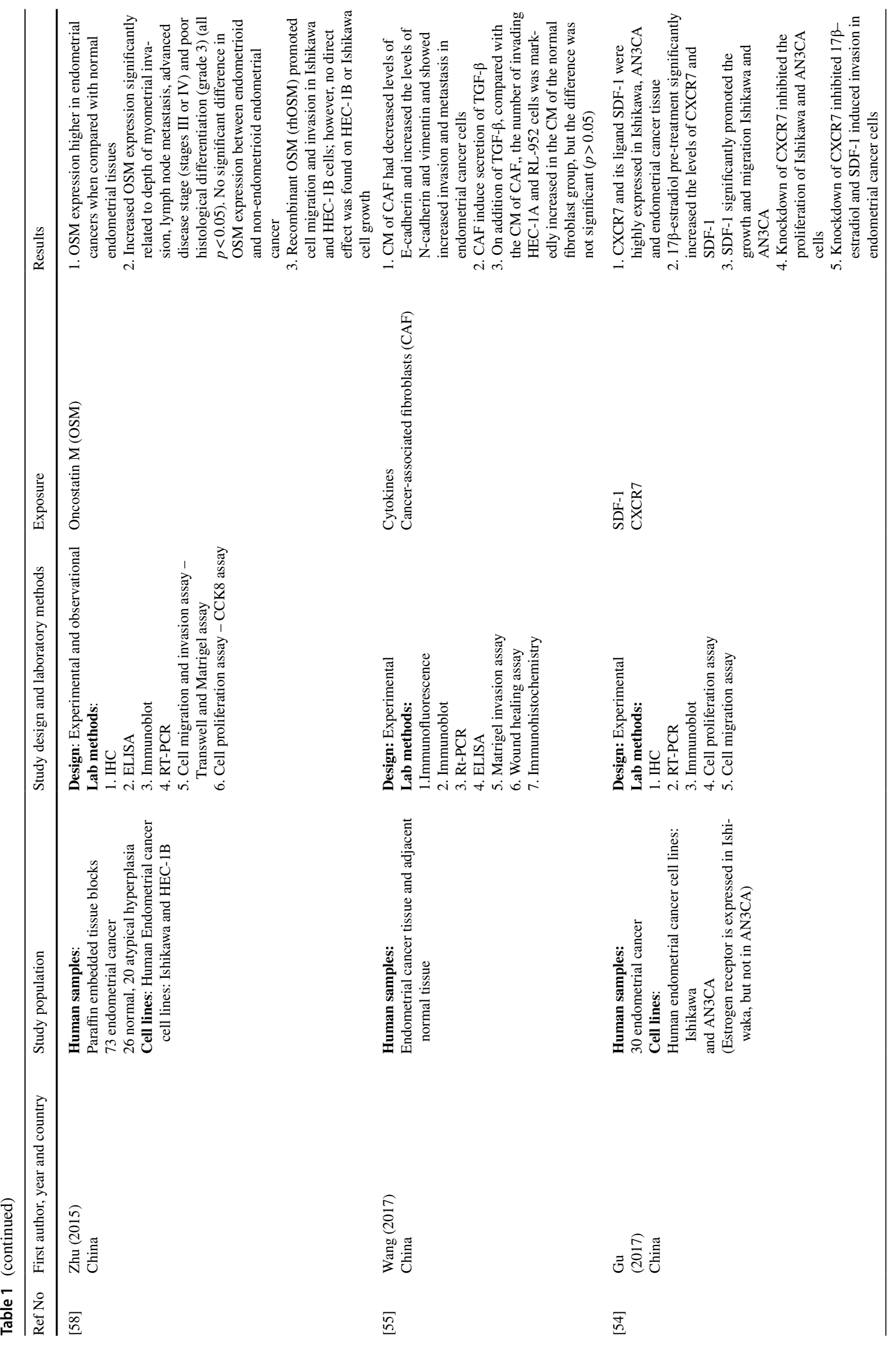




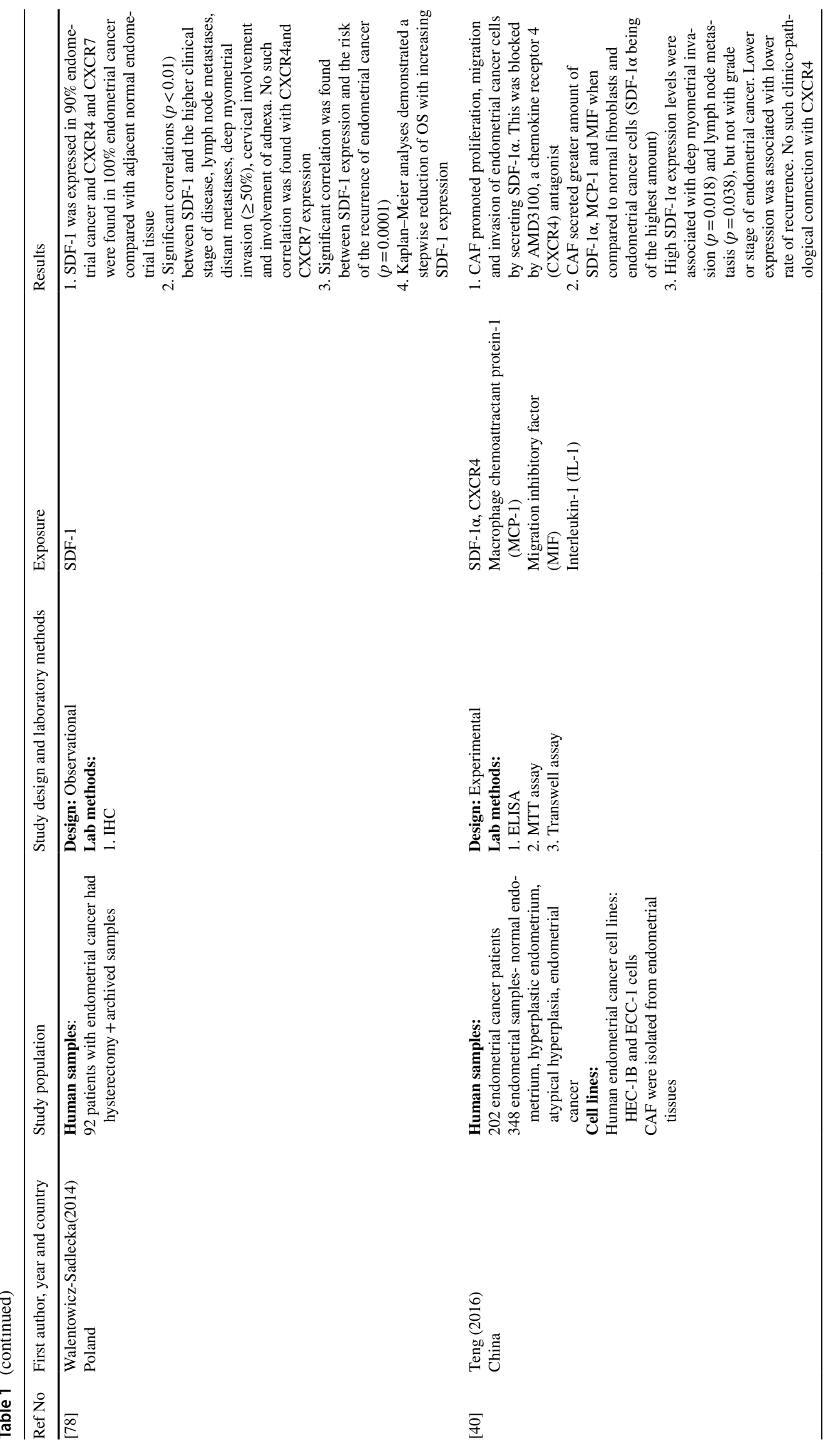




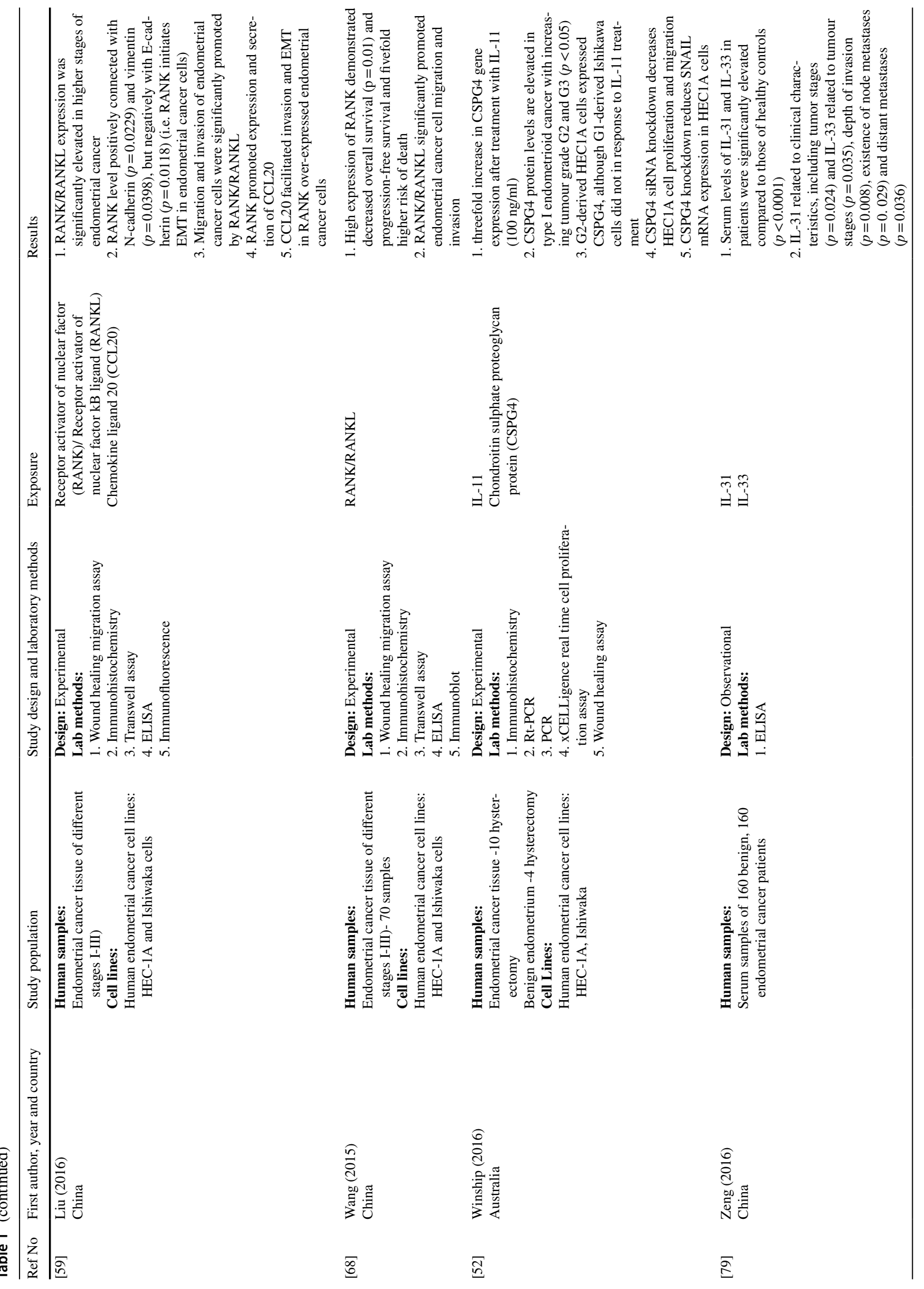




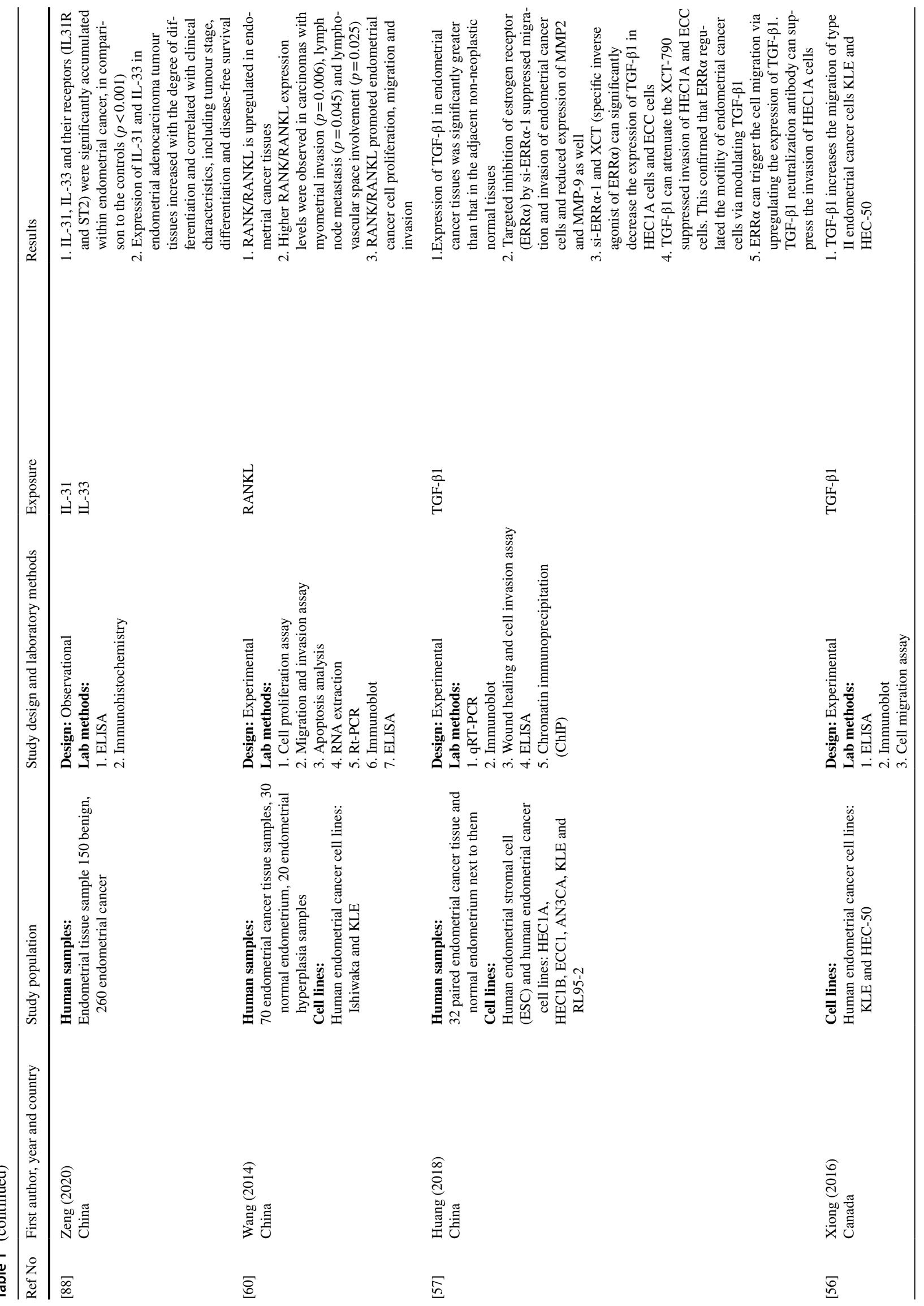




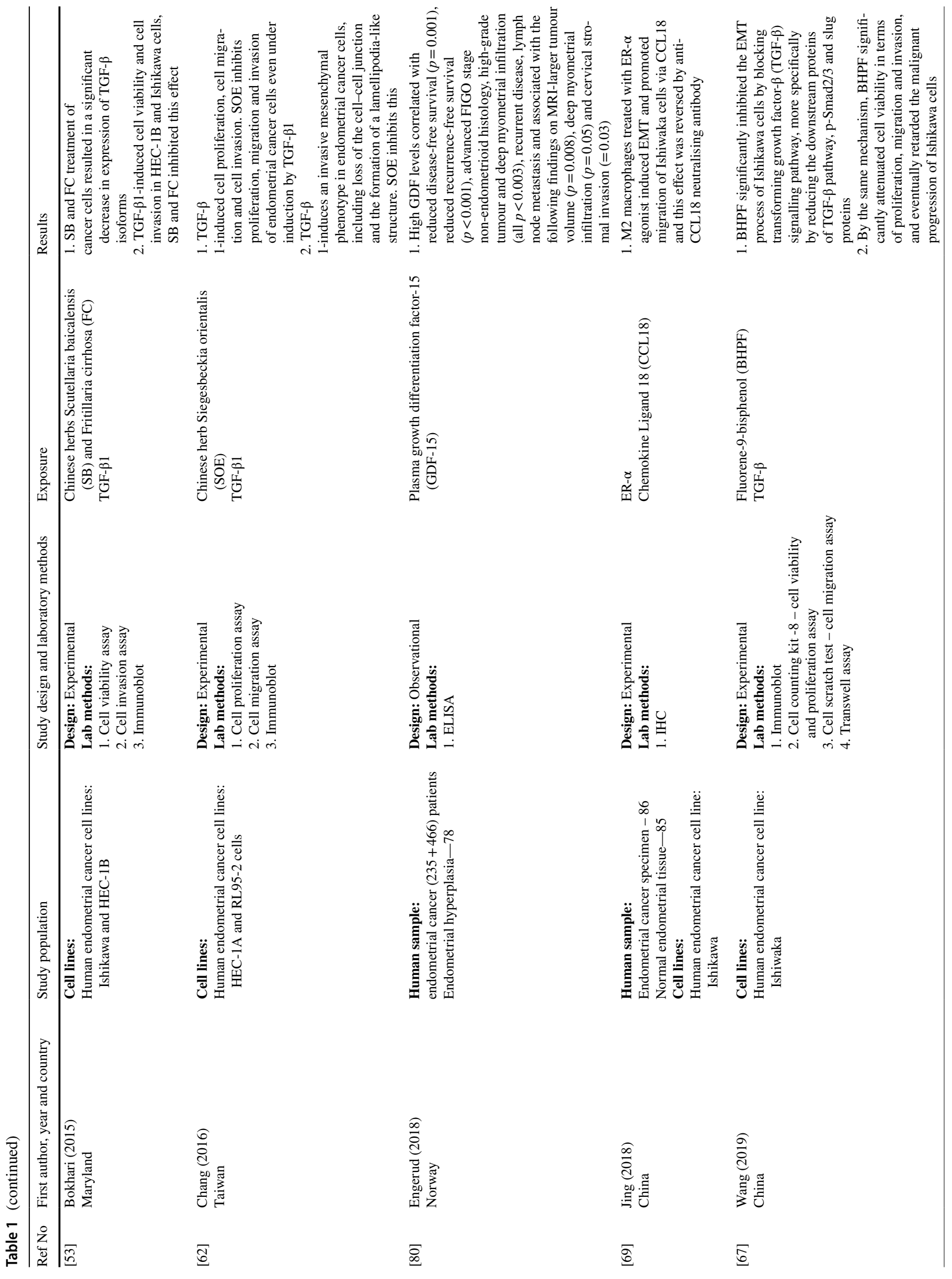




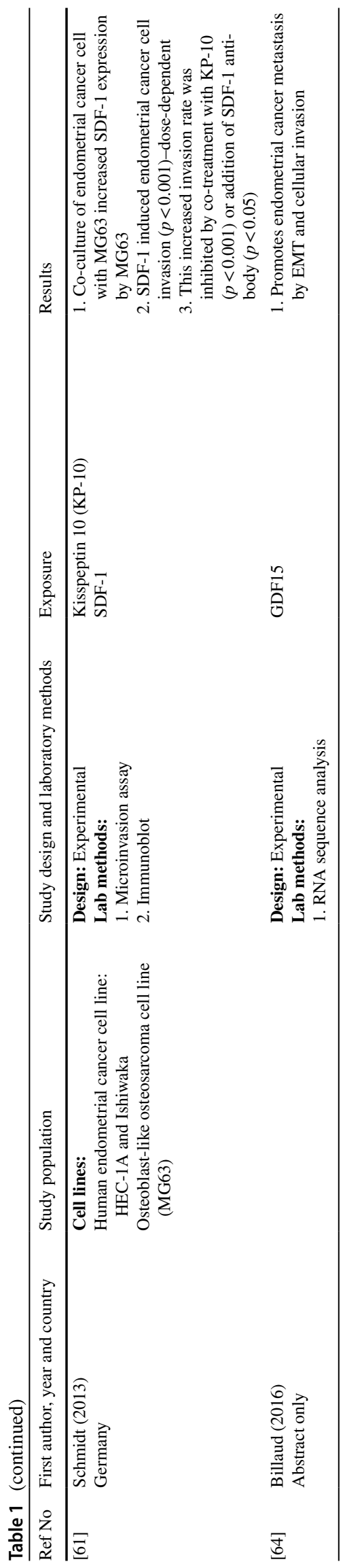

Publisher's note Springer Nature remains neutral with regard to jurisdictional claims in published maps and institutional affiliations. 